\title{
A Comparative Study of Boosters in the Discussion Section of Medical and Applied Linguistics Articles
}

\author{
Islam Namazian Dost ${ }^{1 *}$ \\ ${ }^{\prime}$ Department of English Language Teaching, Ahvaz Branch, Islamic Azad University, Ahvaz, Iran
}

Corresponding Author: Islam Namazian Dost, E-mail: e.namazi75@yahoo.com

\section{ARTICLE INFO \\ Article history \\ Received: May 15, 2017 \\ Accepted: July 02, 2017 \\ Published: December 01, 2017 \\ Volume: 6 Issue: 7 \\ Special Issue on Language \& Literature Advance access: September 2017}

Conflicts of interest: None Funding: None

\begin{abstract}
This study tried to investigate the role of interpersonal meta-discourse markers such as boosters. In order to illuminate this relation, 15 medical and 15 applied linguistics articles were selected randomly from around 50 articles. Therefore, quantitative and qualitative methods were applied to answer the research questions to identify the frequency and percentage of booster employment in their discussion sections. Moreover, to determine the supposedly meaningful differences between booster applications in the corpus, the chi-square test was used. The findings showed that there was not any significant difference between applied and medical articles in using boosters in their discussion section. Moreover, it was found that boosters such as it is clear that, definitely, certainly, really, totally, always were the most frequent ones which were used in two groups of articles namely applied and medical articles. Since meta-discourse markers, i.e., boosters play crucial roles in mediating the relationship between what writers intend to argue and their discourse communities, the results of the present study have obvious importance in increasing students' awareness of the way they organize their writings.
\end{abstract}

Key words: Discourse Analysis, Meta-discourse Markers, Boosters

\section{INTRODUCTION}

\section{Preliminaries}

Discourse analysis is viewed as an investigation of language being used. Barton (2004) characterizes it as a "system for breaking down the ways that particular elements of language add to the translation of writings in their different connections (p.57). The implying that would be derived from this definition is that discourse analysts not only are attempting to give an itemized examination of content, but also plan to look past the significance of sentences to consider the effects that members, circumstances, objectives and after effects of a connection will have on content, too. Therefore, discourse analysis acknowledges frames and elements of a language and in addition its social and social components. Additionally, it would prompt a superior comprehension and a successful correspondence. Schiffrin (1994) accepted six different hypothetical perspectives and expository methodologies toward discourse analysis: speech act theory, interactional sociolinguistics, ethnography of communication, pragmatics, conversation analysis and variation analysis. In spite of the fact that these methodologies high light an alternate part of language use, yet the shared view for every one of them is to consider dialect as a method for association and social correspondence. One of the assets that would be useful for understanding this fact is meta-discourse markers, i.e., boosters.
Boosting, likewise called intensifiers or sureness markers reciprocally, is an issue examined under meta-discourse. It makes a vehement impression in the peruse, that is, an impression of sureness, conviction and confirmation. In other words, boosters may be thought as meta-discourse markers aiming to strengthen writers' claims on the issue, accordingly a heftier conviction impact on the stockholder. Along similar lines, they might be thought as meta-discourse markers meaning to reinforce scholars' cases on the issue, in like manner a heftier conviction sway on the stockholder. Along comparable lines, they have a reason for expanding the suggestions, and demonstrate the essayist's engagement and duty to his/her announcements (Hyland, 1998). In brief, boosters are power markers that demonstrate the creator's position on a monster scale by narrowing desultory space.

Boosting has dependably been concentrated together with hedging, which is a de-intensifier proclamation and a provisional dialect to diminish the essayist's dedication. While there exist a few studies directed just on hedging, boosting shockingly has been maintained a strategic distance from to be examined unmistakable from hedging. With an unequivocal speech, it has stayed under the shadow of supporting due to co-handling. Along these lines, a study that plunges into specific keeping in mind the end goal to examine decided expressions would be of most extreme significance to ready to increase further knowledge into boosting. 
On the highest point of this, now that a paper is composed to change over information to another or to bolster the thought by persuading the peruses, boosting is an irreplaceable part to understand that go for the creators. More, it is hard to gage the impact of composing over the crowd; however through boosting it might be conceivable to build the effect level by expressing the determination.

As previously stated, the high larger part of the studies in the literature directed the issue dichotomously; supporting and boosting which is prone to end with deficient consideration as far as boosting in light of the fact that it for the most part disparaged when concentrated on with hedging. Along these lines, there appears a scarcity of studies directed just on boosting. Moreover, the studies in the analyzing so as to write demonstrate that they were directed surface etymological elements of sponsors however not different components that could be imperative like diverse. Vague information on multifaceted variables as respects boosting makes it penniless to examine the issue inside and out on whether the way of life of the writer, and in addition surface etymological elements, has any impact on the utilization of power markers in his/her compositions.

The present study aims to investigate two types of articles namely medical and applied linguistic articles. On account of the present study, culturally diverse effects on utilizing supporters and phonetic contrasts on the inclination of boosting gadgets will be resolved through a progression of writing filtering and measurable tests. Toward the end, some window on boosting propensities of medical and applied linguistic authors will be given. Boosting might be thought as the illocutionary power of discourse, so might be dealt with under circuitous discourse demonstrations of Austin (1962) and Searle (1969), as expressed by Holmes (1984, p. 347), altering the illocutionary power of discourse acts includes expanding or diminishing the quality with which the illocutionary point is exhibited". The dedication in the illocutionary power might offer ascent to the perlocutionary demonstration by adding to the impact of the talk; that it, to concretely affect the stockholder. Another issue that should be explored is the size of boosting in scholarly messages. Since responsibility positively affects conviction of the peruse on the talked about issue of the content; the more the maker utilizes boosting gadgets in his/her messages the higher agreeableness level she or he is going to reach. That clear rationale does not bode well by any means. So what we know, as expressed by Hyland (1998b), is that there should be a balance concerning the measure of utilization of boosting gadgets in scholastic writings. Through abusing force markers, it is conceivable to make a counter-impact with the peruse and decrease the validity of the announcements on the grounds that much proof would be expected to cover excessively emphatic or testing positions. An exploration led by Kaplan (1976) demonstrated that the utilization of meta-discourses, especially power markers, in writings differs crosswise over one dialect and society to another. That is to say, meta-discourses like supporting and boosting in a dialect and society are not commensurate to the one in another dialect and society. Thus, a study led among a specific society would just give a one of a kind result to the setting it was considered in, and would not be generalizable to different connections; hence metadiscoursal gadgets ought to be disentangled with a particular exploration for every society and dialect. The audited etymological writing demonstrates the nearby connection in the middle of fences and promoters. Numerous studies see the issue bivious as supporting and boosting (for instance see Alward, Mooi, \& Bidin, 2012; Uysal, 2014). Moreover, despite the fact that there exist a few concentrates just directed on supporting (e.g. Nivales, 2011; Yang, 2013), it is hard to experience any study concentrating on boosting for special cases see Wee, 2004; Peacock, 2006; Dobakhti, 2013). The matter with concentrating on supporting and boosting together is that boosting is typically belittled in view of the strong significance paid to supporting gadgets. Those outcomes in tightfisted record of boosting in reciprocal studies which included both supporting and boosting consequently, a study concentrating on just boosting will be of extraordinary significance in giving some breathing space information to the etymological writing, and get kudos from the individuals who prop for an exploration bond with boosting.

\section{Statement of the Problem}

The extent to which research article authors emphasize or deemphasize the truth value of their claims is one of the issues that have for a long time occupied the mind of the researchers in the field of contrastive rhetoric. Although numerous instructive scientists way to deal with the utilization of metadiscourse markers from alternate points of view and explored the part of individual qualities on scholarly written work; however, few, if any, studies probe into the influence of using metadiscourse markers, i.e., booster in educational context in general and in EFL context in particular. Moreover, the researchers could not find any relevant article in the use of this marker in Iranian context. Such gap kindled the researchers to explore the role of using boosters in the abstract of some articles.

\section{Objectives of the Study}

The aim of this study is to examine the use and frequency of boosters in the discussion of research articles authored by academic writers in the field of medical and applied linguistics. In general this study will answer the questions presented below.

\section{Research Questions}

1. Is there any difference between applied linguistics and medical research articles in the use of boosters across their discussion section?

2. What are the most common certainty markers (boosters) that the two groups of writers, namely medical and applied linguistics, employed in their discussion writings? 


\section{LITERATURE REVIEW}

Boosters, in spite of scarcity of studies, have been examined by analysts through distinctive examinations relying upon heap components of them. The etymology writing demonstrates that most of the existent studies focused on cross-disciplinary bases of boosting gadgets. One case for this fits in with Peacock (2006) who had a cross near examination of six scholarly teaches. For him, Language and Linguistics had the most elevated extent of boosting gadgets with 10.98 for each 1000 words when contrasted with other sociology disciplines. Another study (Vázquez \& Giner, 2009) pointed a comparative reason by changing the information source, and found that intensifiers are utilized by researchers as a part of Biology and Mechanical Engineering all around ok yet not as much as in Marketing. The subject of whether delicate sciences or hard sciences incorporate promoters more has charmed to a few researchers (Khedri, Ebrahimi, \& Heng, 2013), and their outcomes proposed that emphatics are required in delicate sciences more than in hard sciences.

Other than cross-disciplinary studies, the writing gives us similar studies which thought about local and non-local scholars of English. Vassivela (2001) found that Bulgarian English writers utilize boosting gadgets more than local journalists of English, particularly in talk parts of their compositions. As needs be, a study (Chen, 2012) led with Chinese English scholars delivered a careful comparable result, and demonstrated that local authors' writings included more grounded statements and more sureness markers than those of EFL Chinese college understudies'. Rather than the both studies showed over, a few researchers (Yazdani, Sharifi, \& Elyassi, 2014), who explored sponsors in media articles, did not say about any factually critical distinction in the middle of American and Persian news articles as far as boosting recurrence.

Another study (Kobayashi, 2009) which meant to distinguish whether Japanese EFL learners or local journalists of English included sponsors in their writings uncovered that Japanese EFL learners were at the absence of lexical varieties of boosting gadgets. Following meta-talk elements like boosting implanted themselves in society particular circumstances, consequently are differential issues as indicated by societies, they ought to be examined by keeping the social elements in the photo. That is, studies pointing the same reason won't give the same results in the settings in which they are explored. In this way, the indeterminacy of studies as respects boosting gadgets can without much of a stretch be seen better from the writing if inspected completely.

Cross-phonetic studies are existent in the writing also. One of the most punctual cross phonetic studies (Cmejrkova, 1996) found that Czech etymologist essayists of English are more disconnected, and utilize more provisional dialect when contrasted with the local journalists of English. As needs be, Chinese understudies are guaranteed to be more emphatic in their L1 compositions than L2 English works (Kim \& Suh, 2014). So it appears that the same writer might change his/her written work style as far as metadiscoursal gadgets relying upon the dialect he or she wants to utilize.

Then again, a few analysts explored hierarchical conveyances of emphatics over the paper. For instance, in a study (Gillaerts \& Velde, 2010) the information of which comprised of just research article abstracts demonstrated that modified works have more fondness with force markers when contrasted with supporting. However there are studies which recommended that discourse and conclusion parts included boosting a great deal progressively when analyzed different parts of an article (e.g. Salek, 2014). While a few studies preferred to concentrate on authoritative disseminations of boosting, a few others preferred to ponder whether there could be any distinctions in boosting as far as exploration outline of the papers. In that sense, experimental and non-observational scholastic articles were gathered and analyzed by $\mathrm{Hu}$ and Cao (2011). Another study (Dobakhti, 2013) separated its information not as observational and non-exact but rather as subjective and quantitative. Besides, it is conceivable to experience with an assortment of studies led on boosting through diverse points and information social events. For instance, Holmes (1990) made a sexual orientation investigation as far as utilizing boosting while Kondowe (2014) concentrated just doctoral understudies compositions', and Aull and Lancester (2014) unhitched male understudies' works.

As expressed in this way, etymology writing conflates differed thinks about on boosting concentrates on under numerous pretenses. Whilst some of them underscore the significance of cross-phonetic contrasts, the others call attention to the likenesses and contrasts in utilizing boosting in the original copies of local English essayists and non-local English authors. Additionally, there are studies intending to distinguish down to earth use of sponsors in unique scholarly trains; to what degree they bear likeness and at what focuses they contrast from each other. As last, it is conceivable to take on studies testing the utilization of emphatics in scholastic writings. Despite the fact that there appears a spurt in the quantity of meta-discourse studies which have a motivation behind inspiring their sober minded or logical capacities in scholarly works, the high larger parts of the studies in the writing block, or if nothing else ignore, the conceivable impact of society in utilizing emphatics. While ponders think about measurable and semantic variable to ready to achieve a sensible result, the end product might lie under certain society based justifications. Thus, on the off chance that it won't be excessively decisive, making it impossible to say, the parochial studies in the writing forecast the present study to research the issue from an alternate point of view that different studies neglected to take note.

\section{METHODOLOGY}

\section{The Corpus}

The corpus comprises of 15 discussions in medical and 15 discussions in applied linguistics written in English. Discussions are chosen to be analyzed partly as a result of their sensible length and minimal presentation of contention, yet for the most part in light of the fact that this is a high stakes kind where scholars must frontal area both the fundamental cases of the paper and their significance (Hyland, 2000). These two disciplines, i.e., medical and applied linguistics 
were selected as representatives of two broad disciplines of medical and Social Sciences. Research articles were drawn from the leading journals of applied Linguistics and medical Engineering published between 2011-2015. To make the corpus data comparable, all of the chosen articles were matched in length. This study explored discussion sections of research articles.

\section{Procedures}

The discussion section of the articles was precisely read word by word in order to identify and locate the boosters. In the stage of analysis, concerning the frequency and types of booster markers, the manual frequency count as opposed to the machine supported strategies was used to have a record of the number of words and the specified boosters through the examined theses. All the data was dissected twice by the researcher to maintain a strategic distance from any missteps in distinguishing and figuring the quantity of boosters in the entire corpus. Therefore, this study used intra-rater reliability. In order to find how the frequency of occurrence of the types of booster markers is significantly relevant in the two groups of articles samples, the chi-square test for which the significance value was set at 0.05 was employed. The assumptions of chi-square test, i.e. normal distribution and homogeneity of variance were also tested in this study, to check whether they are met or not. The result of test of normality shows that the value is not significant ( $p>0.05$ ) which emphasizes normality.

\section{RESULTS}

Table 1 shows the frequency of boosters in discussion section of applied and medical articles.

As the table shows in applied articles Booster were used 28 times $(40.6 \%)$ and in the medical articles 41 times $(59.4 \%)$.

As the type of variable was countable, so the researcher was used chi-square test. The null hypothesis is the equal use of boosters in the abstract section of medical and applied articles.

Descriptive statistics and test results are provided in Table 2.

The frequency use of booster in applied and medical articles is 41 and 28 times respectively. As the table shows the significance level is 0.118 which is higher than 0.05 , so the null hypothesis is accepted and applied and medical papers have used the booster equally in their discussion parts.

Figure 1 shows the results in Table 2. Similar Latin letters showed no significant difference.

\section{DISCUSSION AND CONCLUSION}

With regard to the first question of the study "is there any difference between applied linguistics and medical research articles in the use of boosters across their discussion section?', the researcher used the chi-square test and the sig. level was higher than .05, so applied and medical papers have used the booster equally in their discussion parts.

The second question of the study "what are the most common certainty markers (boosters) that the two groups

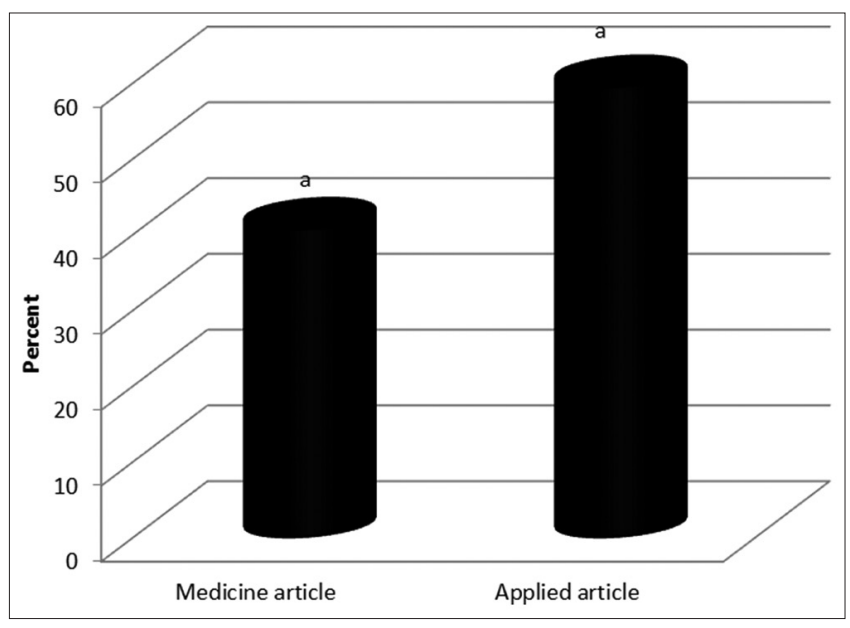

Figure 1. Booster in applied and medical articles

Table 1. Frequency of boosters

\begin{tabular}{lc}
\hline & Frequency (\%) \\
\hline Medical article & $28(40.6)$ \\
Applied article & $41(59.4)$ \\
Total & $69(100.0)$ \\
\hline
\end{tabular}

Table 2. Frequencies \& test statistics of booster

\begin{tabular}{lccc}
\hline & Observed N & Expected N & Residual \\
\hline Medical article & 28 & 34.5 & -6.5 \\
Applied article & 41 & 34.5 & 6.5 \\
Total & 69 & & \\
Chi-Square & 2.449 & & \\
df & 1 & & \\
Asymption & 0.118 & & \\
signature & & & \\
\hline
\end{tabular}

of writers, namely medical and applied linguistics, employed in their discussion writings?", the researcher through investigating the discussion parts, concluded that boosters it is clear that, definitely, certainly, really, total$l y$, always were the most common ones which were used in two groups of articles namely applied and medical articles.

In conclusion, it was found that journal writers differentiated in the use of boosters to express certainty. Additionally, it is noteworthy to mention that both applied and medical articles showed a substantially higher use of boosters.

\section{REFERENCES}

Alward, A., Mooi, C., \& Bidin, S. (2012). Hedges and Boosters in the Yemeni EFL Undergraduates' Persuasive Essay: An Empirical Study. The Internet Journal of Language, Culture and Society, 34, 1-12.

Aull, L., \& Lancester, Z. (2014). Linguistic Markers of Stance in Early and Advanced Academic Writing: A Corpus-based Comparison. Written Communication, 31(2), 151-183. http://dx.doi.org/10.1177/0741088314527055. 
Austin, J. (1962). How to do things with words. Oxford: Oxford University Press.

Barton, E.L. \& Stygall, G. (2004). Discourse Studies in Composition. Cresskill, NJ: Hampton Publisher, 2002.

Cmejrkova, S. (1996). Academic writing in Czech and English. In E. Ventola, \& A. Mauranen, Academic writing. Intercultural and textual issues (pp. 137-152). Amsterdam/Philadelphia: John Benjamins. http://dx.doi org/10.1075/pbns. $41.11 \mathrm{cme}$.

Chen, Z. (2012). Expression of Epistemic Stance in EFL Chinese University Students' Writings. English Language Teaching, 5(10), 173-179. http://dx.doi.org/10.5539/elt. v5n10p 173.

Dobakhti, L. (2013). Expressing Certainty in Discussion Sections of Qualitative and Quantitative Research Articles. Pan-Pacific Association of Applied Linguistics, 17(1), 57-77.

Gillaerts, P., \& Velde, F.V. (2010). Interactional metadiscourse in research article abstracts. Journal of English for Academic Purposes, 9, 128-139. http://dx.doi. org/10.1016/j.jeap.2010.02.004.

Holmes, J. (1984). Modifying illocutionary force. Journal of Pragmatics, 8, 345-365. http://dx.doi.org/10.1016/03782166(84)90028-6.

Holmes, J. (1990). Hedges and Boosters in Women's and Men's Speech. Language \& Communication, 3, 185205. http://dx.doi.org/10.1016/0271-5309(90)90002-S.

Hu, G., \& Cao, F. A.-a.-m. (2011). Hedging and boosting in abstracts of applied linguistics articles. Journal of Pragmatics, 43, 2795-2809. http://dx.doi.org/10.1016/j. pragma.2011.04.007.

Hyland, K. (1998). Boosting, hedging and the negotiation of academic knowledge. Text, 18, 349-382. http://dx.doi. org/10.1515/text.1.1998.18.3.349.

Hyland, K. (2000). Hedges, Boosters and lexical invisibility: noticing modifiers in academic texts. Language Awareness, 9(4), 179-197. http://dx.doi org/10.1080/09658410008667145.

Kaplan, R. (1976). Cultural thought patterns in intercultural education. Language learning, 16, 1-20. http://dx.doi. org/10.1111/j.1467-1770.1966.tb00804.x.

Khedri, M., Ebrahimi, J., \& Heng, S. (2013). Interactional Metadiscourse Markers in Academic Research Article Result and Discussion Sections. The Southeast Asian Journal of English Language Studies, 19(1), 65-74.

Kim, C. H., \& Suh, H. W. (2014). Epistemic Rhetorical Stance: Hedges and Boosters in L1 and L2 Students' English Writings. The Linguistic Association of Korea Journal, 22(2), 61-93. http://dx.doi.org/10.17154/ kjal.2014.03.30.1.61.
Kobayashi, Y. (2009). Extracting characteristics of English essays written by Japanese EFL learners. Proceedings of Jinmonkon Symposium Series of Information Processing Society of Japan (pp. 261-268). Osaka: Information Processing Society.

Kondowe, W. (2014). Hedging and boosting as interactional metadiscourse in literature doctoral dissertation abstracts. International Journal of Language Learning and Applied Linguistics World, 214-221.

Nivales, M. (2011). Hedging in College Research Papers: Implications for Language Instruction. Asian EFL Journal, 35-45.

Peacock, M. (2006). A cross-disciplinary comparison of boosting in research articles. Corpora, 1(1), 61-84. http://dx.doi.org/10.3366/cor.2006.1.1.61.

Salek, M. (2014). A Diagram of Interactive and Interactional Markers in Different Parts of English Research Articles. Journal of Language Sciences \& Linguistics, 2(3), 55-66.

Schiffrin, D. (1994). Approaches to discourse. Oxford: Blackwell.

Searle, J. (1969). Speech acts. An essay in the philosophy of language. Cambridge: Cambridge University Press. http://dx.doi.org/10.1017/CBO9781139173438.

Uysal, H. (2014). A Cross-cultural Study of Indirectness and Hedging in the Conference Proposals of English NS and NNS Scholars. Occupying Niches: Interculturality, Cross-culturality and Aculturality in Academic Research, 179-195. http://dx.doi.org/10.1007/978-3-31902526-1 12.

Vassileva, I. (2001). Commitment and detachment in English and Bulgarian academic writing. English for Specifc Purposes, 83-102. http://dx.doi.org/10.1016/ S0889-4906(99)00029-0.

Vázquez, I., \& Giner, D. (2009). Writing with Conviction: The Use of Boosters in Modelling Persuasion in Academic Discourses. Revista Alicantina de Estudios Ingleses, 22, 219-237.

Wee, L. (2004). Extreme communicative acts' and the boosting of illocutionary force. Journal of Pragmatics, 36, 2161-2178. http://dx.doi.org/10.1016/j.pragma.2004.01.001.

Yang, Y. (2013). Exploring linguistic and cultural variations in the use of hedges in English and Chinese scientific discourse. Journal of Pragmatics, 50, 23-36. http://dx. doi.org/10.1016/j.pragma.2013.01.008.

Yazdani, S., Sharifi, S., \& Elyassi, M. (2014). Interactional Metadiscourse in English and Persian News Articles about 9/11. Theory and Practice in Language Studies, 4(2), 428-434. http://dx.doi.org/10.4304/ tpls.4.2.428-434. 